\title{
A Summary of the Research on Resource Patching of Social Entrepreneurship
}

\author{
Ge Dengke ${ }^{1, \mathrm{a} *}$ \\ ${ }^{1}$ School of Business Administration, Zhejiang Gongshang University, Hangzhou, Zhejiang, China \\ a*1042639874@qq.com
}

\begin{abstract}
At present, scholars at home and abroad pay great attention to social entrepreneurship research, which is growing into a new research field. Social enterprises increasingly show obvious flexibility and control over various resources, and are gradually growing into an important force to promote social innovation and change. Based on the existing resource patching research, this paper continues to explore the resource patching methods of social entrepreneurship.
\end{abstract}

Keywords: entrepreneurship, social entrepreneurship, resource patchwork

\section{社会创业的资源拼凑研究综述}

葛登科 $1, \mathrm{a}$ *

${ }^{1}$ 浙江工商大学工商管理学院, 杭州, 中国

a*1042639874@qq. com

\section{摘要}

当前, 国内外学者对社会创业研究给予极大的关注, 社会创业研究正成长为一个崭新的研究领域。社 会企业日益显示出明显的灵活性和对各种资源的掌控力, 正逐渐成长为推动社会创新和变革的重要力 量。本文基于现有的资源拼凑研究基础上，继续探寻社会创业的资源拼凑方式。

关键词：创业，社会创业，资源拼凑

\section{1. 前言}

自 20 世纪 90 年代以来, “运用市场机制致力于社 会价值的创造” 或者是 “通过创新的方法解决社会问题” 的社会创业实践活动不断受到相关学者和实践者的关注, 并且已经成为了国内外学者们研究的 “热点” 和 “焦点” 问题之一。社会创业是指利用创业技能对社会问题作出 创新的反应。它的目标是希望能够通过其商业手段为客 户提供商品和服务, 实现自身发展与创造社会价值的双 重目标。社会企业的目标群体多集中于养老、教育、助 残、脱贫、就业、环保等社会生活领域, 深感社会重任的 社会企业家便投身其中, 用社会企业的形式惠及更多受 众, 解决相关的社会问题。由于社会创业企业在运用商业 手段创造社会与商业的双重价值方面取得了显著的成果, 社会创业已经成为社会变革与发展的重要动力。社会企 业的兴起, 也引发了中国学术界的广泛关注, 得到了主流 创业和管理学研究的日益关注, 成为学界的热点议题。来 自公共治理、社会学、管理学等学科的学者从社会企业 的定义、内涵、类型、社会企业成长等方面对其进行研
究, 但是现实中,很多社会创业组织自身商业模式的缺乏 往往阻碍了其公益性和商业性的平衡。社会创业需要认 识到机会, 结合和调动资源, 引发各个领域的积极变化, 并建立可持续性。

\section{2. 国内外文献综述}

\section{1. 社会创业的兴起与发展}

“社会创业” (social entrepreneurship)一词由 阿苏迦基金会 (Ashoka) 的 创始人 德雷顿 (WilliamDrayton) 在 20 世纪 80 年代创造, 随后狄兹 (J. Greg-oryDees) 在《社会企业家的含义》这篇文章 中，对这个词语又进行了解释。社会企业多集中于助残、 助贫及特殊社会问题领域。在企业追求利益最大化和政 府的福利政策陷入僵局的情况下, 社会企业随之出现。

关于社会创业的定义在文献中有 37 种之多。有些学 者指出, 社会创业实际上是各种商业机构、非营利组织及 政府等合作, 进行的社会价值的创造 ${ }^{[1]}$ 。Choi 和 Ma jumdar 
止到目前为止, 学界尚未建立一套明确的理论系统。社会 企业在进行社会价值的创造时, 商业模式占据着极其重 要的地位, 它通过各种经营方式创造社会价值, 而想要确 保其持续健康发展, 就需要建立新型的商业模式。

严中华等将印度 Aravind 眼科医院这个具有代表性 的社会创业公司作为研究案例, 分析了它的商业模式, 研 究得出 Aravind 眼科医院的商业模式是顾客界面、战略 资源、核心战略以及价值网络等要素的充分结合 ${ }^{[8]}$ 。社会 创业企业商业模式的组成要素, 并不是单方面的, 包括价 值主张、盈利模式、经营战略、价值网络、资源配置、可 持续发展力等 ${ }^{[9]}$ 。在进行社会创业时, 所涉要素主要包括 五方面, 分别是社会创业者、资源、机会识别、社会网络 以及合法性等, 社会创业企业在创业和企业成长过程中 始终要协调好五种要素之间的关系 ${ }^{[10]}$ 。

作为一种弥补政府与市场不足的创新的组织形式, 社会创业组织在解决社会问题中创造经济效益与社会价 值方面有十分显著的意义。随着我国改革开放的逐渐深 入, 在政府推动的 “大众创业, 万众创业” 的新潮流下, 各种类型的创业组织的兴起与发展渐渐成为了新的时代 趋势。其中社会创业其本身所蕴含的经济和社会双重价 值创造目标的特点也符合社会发展的需要。

其中猪八戒网络平台就是一个典型的例子, 平台上 注册的残疾人服务商已超过 10000 人, 出于对企业社会 价值的实现考虑, 猪八戒网络平台成立了 “八戒阳光” 版块帮扶残疾人更好的就业、创业 ${ }^{[5]}$ 。

\section{2. 社会创业与商业创业的区别}

社会企业不同于传统企业, 后者将商业模式视为核 心竞争力, 但是社会企业认为商业模式主要是用于获取 更多的合法权利。社会创业组织的商业模式主要是在获 取必要的经济价值的前提下, 创造更多的社会价值, 并做 到两种价值要素完美整合。Shaneand Venkataram 融合了 不同社会学科, 提出了适用于社会创业和传统创业的内 涵体系, 强调无论是哪种创业形式, 对于什么热闹使用什 么方式, 发现、创造、探索和评价未来产品和服务给予了 高度关注。其中社会创业者对社会进行双重价值创造时 更关注社会问题的解决, 并且不存在固定的商业模式与 行为准则。Doherty B, Spear R 在英国一系列商业部门的 社会企业的一些案例研究的基础上, 开发了一个概念框 架适应创业精神的集体或多元层面。这项小规模的探索 性研究提供了有趣的创业模式, 与中小企业的传统模式 形成了对比 ${ }^{[6]}$ 。此外, 有学长研究表明, 社会企业和商业 企业的商业模式中都涉及核心战略、顾客边界、战略资源 和价值网络几部分, 但在目标群体、定价方式、支付行为、 轻资产低投入等方面有所不同 ${ }^{[7]}$ 。

\section{3. 社会创业的商业模式}

因社会创业的兴起时间不是很长, 各类社会创业组 织在社会问题的解决方面, 没有固定的解决模式, 而且截

\section{4. 创业的资源拼凑}

现代创业较之过去的更注重资源的拼凑理论, 并将 资源拼凑理念带入到创业的具体操作运营之中。确定企 业家所需要的关键技能和能力, 突出新资源组合的方式, 对于成功的商业创造至关重要 ${ }^{[11]}$ 。

Heirman A, Clarysse B 研究了新组织所基于的初 始资源, 以及这些资源如何与机构来源和市场特征相互 作用。发现了四种不同的启动配置: “风险投资支持的初 创企业”、“勘探者”、“产品初创企业” 和 “过渡性初 创企业”。同时发现一半的公司是以勘探者的身份开始 的, 由 VC 支持的初创企业是少数 ${ }^{[12]}$ 。

有些学者在进行共享经济商业模式的创新研究时, 引入了资源拼凑的概念, 对共享经济下, 企业商业模式创 新过程中的资源拼凑方式进行了探讨, 提出, 通过资源拼 凑对企业商业模式的实施方案进行革新 ${ }^{[13]}$ 。通过实例研 究可以得知, 资源拼凑将从正面影响社会创业, 而且能对 创业失败的原因进行分析 ${ }^{[14]}$ 。创业网络可以为新的创业 公司取得资源, 突破现有资源困境, 同时也能帮助企业将 潜在资源转化成企业业绩, 这主要由企业对资源的拼凑 能力决定。创业网络对于创业企业的绩效有重大影响, 创 业企业应提高自身资源整合力, 提高资源使用率, 同时加 强创业学习等方面的运用, 特别是要进行探索式学习, 实 现自我成长 ${ }^{[15]}$ 。

在进行资源的拼凑与整合时, 创业企业如若采用并 行拼凑法, 可能会使部分项目资源暂时空置, 而在使用已 拼凑资源时, 可能会因项目状态, 无法确保资源使用率的 最大化。但是运用连续和选择性拼凑, 创业人员只需要集 中现有资源并将其使用价值充分发掘出来, 以投入到项 目开发中即可, 继而帮助企业创造更多的发展机会。

\section{5. 社会创业的资源拼凑}

目前社会创业已经成为国内创业活动的核心组成部 分, 当资源不够充分时, 对于社会创业资源的拼凑, 有助 于社会创业理论和资源拼凑理论的丰富和完善。社会创 
因此, 资源拼凑有助于社会创业的发展。目前的研究大多

业需要识别和发现新的创业机会, 需要持续不断的创新、 学习、适应外部环境 ${ }^{[16]}$, 但是社会创业常常面临资源束缚 的困境，因而资源拼凑成为当前创业领域中关注的焦点。 在对社会创业资源进行整合时可以发现, 社会创业人员 的拼凑力越强, 资源价值发挥的越充分 ${ }^{[17]}$ 。机会是社会创 业活动的核心要素, 但是没有社会创业者的资源和能力, 创业机会不可能被发现、实施、进而实现社会和商业价值。 社会创业者善于创造性地利用外部资源来应对制度障碍， 其中外部资源包括关系资源、文化资源、制度资源 ${ }^{[18]}$ 。

社会创业人员可以通过积极的态度, 号召社会各界 人士, 建立相互理解、互助互信的关系, 继而将各类社会 资源和关系充分调动起来, 以实现创业目标。对于社会企 业的发展来说, 资源拼凑有助于创造社会价值, 发掘价值 增长潜力。促进经济与社会价值间的连接, 主要是通过资 源拼凑实现的 ${ }^{[19]}$ 。彭伟等通过扎根的理论和方法, 对我国 八家创业类公司进行了分析, 对社会创业公司中, 资源拼 凑的概念及发展演变进程进行的分析和研究。通过研究 可以得出, 社会创业公司的拼凑活动主要来自人力资源、 社会实物、互联网、技术能力、制度及市场等方面。除此 以外, 不同发展阶段, 社会创业公司都需要采取不同的资 源拼凑方式, 以推进企业发展; 创业阶段的社会拼凑, 主 要以实物和人力拼凑为主; 生存阶段的社会拼凑, 主要以 技术能力拼凑为核心; 成长阶段的社会拼凑, 主要以市场 和体制拼凑为核心 ${ }^{[20]}$ 。通过资源拼凑和组织合法性理论 研究可以得知, 资源拼凑的种类不同, 创业公司所取得的 组织合法性理论不同。实物、技能以及市场等拼凑方式, 可以帮助企业取得合法市场地位, 提高企业的经济效益; 制度和人力拼凑, 可以帮助企业取得合法的社会地位, 为 企业创造社会价值, 促进企业成长与发展 ${ }^{[21]}$ 。

\section{3. 注意事项}

本文回顾和述评了基于资源拼凑理论的社会创业研 究文献, 结合资源拼凑方式和社会创业相关情境因素, 分 析了资源拼凑理论视角下的社会创业。根据资源拼凑理 论, 创业的资源拼凑就是创业者利用现有资源进行开发 创业。当然, 这需要创业者对于现有资源进行创造性的整 合利用。故而, 社会创业的资源拼凑其实质是从新的角度 看待创业过程中的资源整合价值。本文通过理论层面的 分析并适当结合了一些具体事例, 发现社会创业的资源 拼凑方式的选择对于创业的绩效有着至关重要的作用。

资源拼凑的方式和资源潜在价值的实现之间存在直 接的关联, 所以资源拼凑的方式对社会创业的发展有十 分显著的影响。目前的研究大多是对社会创业以及资源 拼凑的现象进行描述和归纳, 有关社会创业的概念、社会 创业的特征、社会创业的发展以及社会创业企业的剖析 等研究成果丰富, 但鲜有对其价值创造模式的研究。另外, 社会创业的本质是同时创造社会价值和经济价值, 社会 创业组织是如何创造价值的, 如何更好地利用资源创造 更大的价值以取得进一步的发展应该成为研究社会创业 的聚焦点。

资源拼凑与实现资源潜在价值间的关系是直观的,
是对社会创业以及资源拼凑的现象进行描述和归纳, 分 析了社会创业的内涵、基本特征、发展进程等, 并对社会 创业类企业进行了探讨, 但鲜有对其价值创造模式的研 究。除此以外, 从本质上来说, 社会创业不仅能带来社会 价值, 也能创造经济价值, 但是他们是通过什么方式创造 价值, 如何更好地利用资源创造更大的价值以取得进一 步的发展应该成为研究社会创业的聚焦点。

社会创业组织的建立与发展的各个阶段总是受到多 种社会因素的影响, 需要从多个层次和多个视角持续研 究社会创业组织的行动, 这个过程中的复杂性与多阶段 性已有学者通过构建过程模型进行了有效的研究。由此 可以得知, 社会创业阶段的研究有助于提升社会创业的 整体价值。在创业过程中, 企业可以将自身实际情况与各 个发展阶段相结合, 分别调整资源拼凑的重点规划和整 体发展战略。

一些学者在资源拼凑领域研究出的丰富成果对社会 创业企业的建立和成长壮大起到了重要的理论指导作用。 但在以现象驱动居多的社会创业研究中商业创业尚且面 临资源稀缺的困境，社会创业如何应对资源稀缺、社会创 业资源从何而来以及又创造何种结果等基础性问题丞待 解决。

综观现有文献可以发现, 虽然创业资源拼凑理论研 究已经取得了一定的进展, 但总的来说目前仍处在理论 探讨阶段, 主要通过案例分析研究进行理论的检验和完 善。后续相关研究可以从社会创业者在企业发展的不同 阶段的资源拼凑方式选择、企业员工拼凑和企业组织文 化氛围等方面来展开, 分析这些关键因素之间的关系。另 外, 在研究中要注意不同的情境因素对于资源拼凑方式 的作用，从多个视角分析资源拼凑和资源价值实现的过 程。

\section{References}

[1] Mair,J.,\& Marti,I. ( 2009 ) Entrepreneurship in and around institutional voids: A case study from Bangladesh. Journal of Business Venturing, 24: 419-435.

[2] Choi, N., \& Majumdar, S. (2014) Social entrepreneurship as an essentially contested concept: opening a new avenue for systematic future research. Journal of Business Venturing, 29: 363-376.

[3] Battilana, J., \& Dorado, S. (2010) Building sustainable hybrid organizations: The case of commercial microfinance organizations. Academy of Management Journal, 6: 14191440.

[4] Doherty, B., Haugh, H., Lyon, F. (2014)Social enterprises as hybrid organizations: a review and research agenda. International Journal of Management review, 16: 417-436.

[5] Cai Shan. (2019)Research on social entrepreneurship business model of zhubajie network platform [D]. Jiangxi University of Finance and economics. 
[6] Doherty B , Spear R . (2016)Social entrepreneurship: a different model?[J]. International Journal of Social Economics, 33(5/6):399-410.

[7] Gong Qilong.(2019) Social network, institutional logic and business model of social enterprises [D]. Shandong University.

[8] Yan Zhonghua, Jiang Xue, Lin Hai. (2011)Analysis of business model elements combination of social entrepreneurship organizations -- Taking Aravind eye hospital in India as an example [J]. Science and technology management research, 31 (21): 207-210.

[9] Lin Hai, Li Youhuan.(2014) Cross case study on the core elements of business model of social entrepreneurship organizations [J]. Journal of Shandong University of Technology (SOCIAL SCIENCE EDITION), 30 (02): 14-19.

[10] Lu Zhangcheng. (2014)Research on business model innovation of social entrepreneurship organizations under dual value [J]. China business, (05): 175-176.

[11] Jones O , Macpherson A , Jayawarna D . (2013)Resourcing the Start-Up Business (Creating Dynamic Entrepreneurial Learning Capabilities) \| [J]. 10.4324/9780203104569.

[12] Heirman A , Clarysse B . (2004)How and Why Do Research-Based Start-Ups Differ at Founding-A ResourceBased Configurational Perspective[J]. The Journal of Technology Transfer, 29(3_4):247-268.

[13] Liu Kangping, he Xiang. (2019)Research on business model innovation of sharing economy enterprises from the perspective of resource patching [J]. Science and technology and economy, 32 (04): 31-35.

[14] Nie Lei, Shao Jianbing. (2019)Empirical research on resource patching, entrepreneurial failure attribution and entrepreneurial learning $[\mathrm{J}]$. Technology economy and management research, (04): 45-49.

[15] Wang Haihua, Xie Pingping, Xiong Lijun. (2019)Research on the relationship between entrepreneurial network, resource patching and the performance of new enterprises [J]. Management science, 32 (02): 50-66.

[16] Zahra, S.A., Gedajlovic, E., Neubaum, D., \& amp;Shulman, J.M . (2009) A typology of social entrepreneurs: motives, search processes and ethical challenges. Journal of Business Venturing, 24(5): 519-32.

[17] Meyskens, M., Post, P., \& Stamp, L. (2010)Social ventures from a resource-based perspective: an exploratory study assessing global Askoka fellows. Entrepreneurship Theory and Practices, 34(4): 661-680.

[18] Dacin, P. A., Dacin, M. T., \& Matear, M.(2010) Social entrepreneurship: Why we don't need a new theory and how we move forward from here. Academy of Management Perspectives, 24(3): 37-57.
[19] Zhang Xiue, Zhang Kun.(2018) The impact of entrepreneurial orientation on the performance of new social enterprises -- the mediating role of resource patching and the regulatory role $[\mathrm{J}]$. Science and technology progress and countermeasures, 35 (09): 91-99.

[20] Peng Wei, Yu Xiaojin, Zheng Qingling. (2019)A study on the resource patching strategy of social entrepreneurship based on grounded theory [J]. Finance and economics review, (01): 81-90.

[21] Peng Wei, Yu Xiaojin, Zheng Qingling, Zhu Zhenduo.(2018) Resource pooling, organizational legitimacy and the growth of social entrepreneurial enterprises: a multi case study based on grounded theory [J]. Foreign economy and management, 40 (12): 55-70. 